\title{
Las voces militares en los diccionarios de español: el caso de yelmo
}

Francisco Gago Jover College of the Holy Cross

Una de las mayores dificultades que afronta todo lexicógrafo es la distancia espacio-temporal que nos separa de la realidad histórica y cultural objeto de nuestro estudio, esta situación se hace más complicada cuanto más nos adentramos en el pasado de una lengua y nos acercamos a un universo cultural que nos resulta cada vez más desconocido. En el campo de la terminología militar medieval este alejamiento tiene como consecuencia la deficiente definición de algunas voces. El caso de yelmo servirá para ilustrar esta problemática y presentar una posible solución.

Los textos medievales, aunque parcos en información, nos ofrecen suficientes detalles como para percatarnos de la enorme variedad tipológica de yelmos existente: tanto en los materiales de que están hechos, como en las diferentes piezas de que se componen, las diferentes formas y estructuras, los elementos decorativos, etc.

el yelmo que leuaua era de muy buen azero [El emperador Otas de Roma, 60r]

le dio cleopatra vn yelmo et vnas cuyraças todas de oro [Crónica de los conqueridores II, 70v]

luego el cauallero alço la visera del yelmo \& començo de llorar fuertemente $\&$ ella lo conocio que era su ermano \& torno contra el \& fuelo abraçar \& alli fizieron muy gran duelo \& llanto [Libro de don Tristán de Leonís, 27v]

llegado ya a donde la reyna estaua apercibiendo el cauallo para mejor la mesura hazer por la vista de mi yelmo la luz del rostro de luzenda entrevy [Tratado de amores de Arnalte y Lucenda, 163r] 
e el terçero firiol enel yelmo \& el golpe deçendio por el nasal de guisa que todo le acosto contra tierra e en esto cayo el cauallo [Gran conquista de Ultramar (interpolada), 151v]

diol vn colpe de trauiessol tomaua // el casco de somo apart gelo echaua // las moncluras del yelmo todas gelas cortaua // [Cantar de mio Cid, 72v]

estando asy adormjdo sobre la cerujz del cauallo corto le las correas del yelmo e ssacogelo de la cabeça \& lançolo en tierra [Libro del Caballero Zifar, 56r]

el rrey fue maraujllado \& dixole que alçase el yelmo \& el lo alço \& commo el rrey vio la cara \& el paresçer del cauallero bien le paresçio \& dixo uos seades bien venjdo \& sabet que aqui vos seruiran \& faran honor de todo nuestro poder [Cuento de Tristán de Leonís, 50v]

ally andaua bruto que venje por la ljnna del otro bruto que echara de rroma los reyes encubierto la cara de vn yelmo que non era sinon commo aldeano \& la lança que el traya $\&$ las otras armas non las connosçie el çesar [General estoria V, $100 \mathrm{v}]$

el duc godufre aferio otro por ençima de vn yelmo agudo que traye [Gran conquista de Ultramar (interpolada), 50r]

despues metio mano ala espada que traya $\&$ dio tan gran herida a vn cauallero de cataloña que llamauan dalmas por encima de vn yelmo çaragoçano que traya que gelo corto [Gran conquista de Ultramar, 119v54]

a estos dieron armas muy notables \& les dieron yelmos que tenian çimeras por que fuesen conosçidos entre los otros [Nobiliario vero, $79 \mathrm{r}$ ]

arriba alço colada vn grant colpe dadol ha // las carbonclas del yelmo tollidas gela ha // [Cantar de mío Cid, 49v] 
vno el qual hauia nombre xoho dio dauant todos los otros a megaclio j colpe \& echole a tierra \& arapole sus sobreuiestas en su yelmo \& corria \& albino mostrando gelas \& cridando dizia yo he muerto a pirrus [Plutarco I, 167r]

Los estudios sobre el armamento medieval en la Península Ibérica de Bruhn de Hoffmeyer (1972 y 1982) y Soler del Campo (1993), basados principalmente en el análisis de fuentes arqueológicas e iconográficas, confirman esta enorme variedad ${ }^{1}$. En líneas generales se distinguen tres tipos de yelmo²:

Tipo 1: Yelmo de estructura semicónica apuntada que cubre el cráneo y está provista de una pequeña pieza vertical que protege el hueso nasal, de donde toma su nombre. Se documenta desde finales del XI hasta principios del XIII.

Tipo 2: Yelmo de estructura cilíndrica completamente cerrada que protege totalmente la cabeza y el rostro, y descansa sobre el cráneo, teniendo como únicas aberturas las ranuras destinadas a la vista y unos pequeños orificios para permitir la respiración. Se documenta desde el primer cuarto del siglo XIII hasta el primer tercio del XIV.

Tipo 3: Yelmo de estructura cerrada de perfil apuntado o redondeado que protege la nuca y toda la cabeza, dejando al descubierto la cara que es protegida por una vista móvil, sujeta por medio de dos pernos. Se documenta desde el primer tercio del XIV hasta finales del XV.

Esta complejidad tipológica no aparece, sin embargo, reflejada en las definiciones que la mayoría de los diccionarios, generales o especializados, asignan a la voz yelmo . Algunos de ellos, Tesoro de la lengua castellana o española (TLCE) (1995), Diccionario ideológico de la lengua

1 Mélida (1887), Giese (1925), Guerrero Lovillo (1949) y Menéndez-Pidal (1986) hacen referencia también, aunque de forma menos extensa, a las diferencias tipológicas.

${ }^{2}$ La tipología y descripciones están adaptadas de Soler del Campo (1993, 97-114).

${ }^{3}$ Los textos completos de las definiciones pueden encontrarse en el Apéndice que aparece al final de este trabajo. 
española (DILE) (1942) y Diccionario de uso del español (DUE) (1996), optan por una definición básica que indica la función de yelmo como elemento protector de la cabeza sin ninguna diferenciación tipológica adicional. Por el contrario, otros diccionarios, Diccionario de autoridades (DA) (1973), Nomenclátor histórico militar (NHM), Diccionario medieval español (DME) (1986), Diccionario castellano (DC) (1987), Diccionario de la lengua española (DRAE) (1992) y Diccionario general de la lengua española (DGLE) (1997), añaden a esta definición básica la enumeración de todas o algunas de las piezas que componen el yelmo (muelles, goznes, visera, rejilla, morrión, babera); el resultado es una definición restrictiva que excluye alguno de los tipos de yelmo. Finalmente, un último grupo de diccionarios, Diccionario militar etimológico, histórico, tecnológico (DMEHT) (1869) y Glosario de voces de armería (GVA) (1912), asigna definiciones de carácter enciclopédico que, aunque más completas que las presentes en otros diccionarios, fallan en su intento de mostrar la diversidad tipológica4.

El problema de la pluralidad de significados se ha tenido muy en cuenta durante la elaboración del "Diccionario de términos militares del español medieval" (DTMEM)s, y en un intento de solucionar casos como el de yelmo se ha decidido no sólo asignar definiciones de carácter enciclopédico, sino también incluir un apéndice con ilustraciones que faciliten la comprensión de conceptos alejados de nuestra realidad cotidiana. Yelmo se define de la forma siguiente:

Arma defensiva de la cabeza. Entre los siglos XI y XII tiene forma semicónica apuntada con una pequeña pieza vertical, el nasal, para proteger la nariz. La insuficiencia defensiva obliga al cierre progresivo de la pieza metálica, llegando a ser en el siglo XIII una estructura cilíndrica completamente cerrada que protege la totalidad de la cabeza, con vista fija y unos

4 El Diccionario militar $(D M)$ (1897) ha sido excluido de este análisis pues la definición que asigna a yelmo 'Nombre de origen gótico, sinónimo en Castilla de «celada»', simplemente remite a otro lema, celada, 'Variedad del casco', sin proporcionar ningún otro tipo de explicación.

5 El DTMEM es un diccionario histórico y descriptivo cuyo principal objetivo es recoger el léxico militar empleado en las zonas de habla castellana, leonesa y aragonesa de la Península Ibérica entre los siglos XIII y XV, documentando todos los vocablos en su contexto. El DTMEM formará parte del diccionario histórico del español, proyecto desarrollado por el Hispanic Seminary of Medieval Studies en la Universidad de Wisconsin-Madison. La metodología empleada en la elaboración del diccionario se describe en Burrus (1987). 
pequeños orificios para permitir la respiración. La evolución hacia formas más funcionales culmina en el siglo XIV con la introducción de una estructura cerrada de perfil apuntado o redondeado que deja al descubierto la cara que es protegida por una vista móvil, sujeta por medio de pernos o goznes.

\section{Diferentes tipos de yelmo}

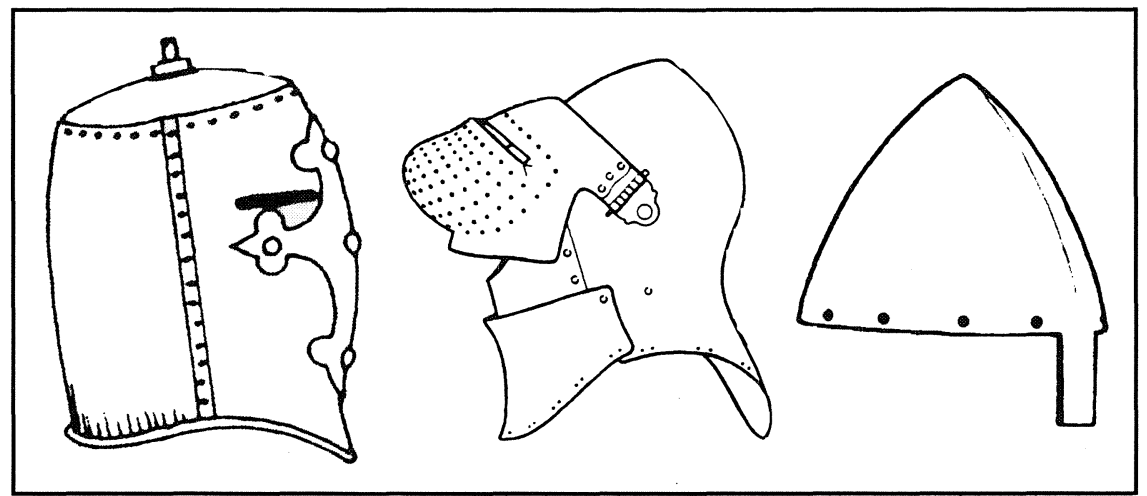

\section{APÉNDICE}

TLCE: Armadura de la cabeza; Latine cassis, seu galea.

DILE: Parte de la armadura antigua que resguardaba la cabeza y el rostro.

DUE: Casco. Parte de la armadura de guerra que cubría la cabeza y el rostro

$D_{A}$ : Parte de las armas antiguas, que los caballeros usaban en las batallas, justas y torneos, y oy sirve de ornato en los escudos de armas, y se componía de varias piezas de acero con sus muelles, y goznes, y servía para defender toda la cabeza, y cara con una pieza, que llamaban viséra, compuesta de una rexilla del mismo acero, con la qual dexaban libre la vista, y en esto se distinguía del morrión, celada, y capacete, de que usaba la Infantería. Es voz derivada del Tudesco Helm, que los italianos dixeron Helmo, y nosotros Yelmo. Lat. Cassis, dis.

NHM: Parte de la armadura antigua que resguardaba la cabeza y el rostro, campaniforme en su origen, después cilíndrico, con diversas modificaciones y pequeña abertura para ver; también llamado "baul de justa", por usarse frecuentemente en justas y torneos.

$D M E$ : Parte de la armadura que resguardaba la cabeza y el rostro, y se componía de morrión, visera y babera. 
Dc: Arma antigua que llevaban los caballeros en la cabeza tanto en la guerra como en los torneos y sirve de adorno en los escudos. fr. heaume, aunque casi sin uso, habillement de tete, casque, lat. galea cassis y otros helmus, pero no se halla en buena latinidad. it. elmo. v. morrión. // Yelmo o celada, sin cresta o penacho. fr. balade, lat. plana galea, depressa cassis, otros no admiten la voz yelmo en castellano sino como distinto de celada y morrion, de modo que el yelmo tenía visera y guardaba cabeza y cara, lo cual no tenía el morrión, sin embargo en Cerv. Quijote, t. 1, cap. 21 llamó yelmo a la vacía del barbero que ciertamente no tenía visera. Como quiera galea significa un resguardo de la cabeza para guerra y los huvo de cuero y cassis lo mismo.

DRAE: Parte de la armadura antigua, que resguardaba la cabeza y el rostro, y se componía de morrión, visera y babera.

DGLE: Parte de la armadura que cubre y defiende la cabeza y el rostro. Se componía de morrión, visera y babera.

DMEHT: Arma defensiva de la cabeza, posterior á la capellina, y sinónima, en España, de celada. Su forma era casi cilíndrica, con unos agujeros pequeños para ver, y varió bastante en los siglos medios; pues desde el IX se adoptó como más fácil forjar un capacete, que se ajustaba á la cabeza por encima del almófar y se enlazaba con correas. Estos yelmos solían estar adornados con cercos de oro y engastes de piedras preciosas. En la punta del espigón que formaba el extremo superior colocaban carbuncos (sic) que, heridos por el sol, relumbraban á mucha distancia. De ambos lados se aseguraba una plancha de hierro que, cubriendo los carrillos y la boca, se le dió el nombre de babera. Luego tuvo visera, ventalla, nasal, etc.

GVA: Celada, casco. Fue durante la Edad Media el tipo más perfecto de la armadura de cabeza y, en su principio, un casco cónico ó cilíndrico con vista fija que descansaba sobre los hombros, exigiendo la capellina de malla cuando dejaba el cuello descubierto. En el siglo XIII se reforzaron con bandas de hierro [...] desde mediados del siglo XIII, se construyeron cónicos, y de aquel tiempo son los grandes yelmos de figura ovoide, de mayor altura que la cabeza del guerrero, sobre cuyos hombros descansaba. Ya en los últimos años del citado siglo, comenzó á preferirse el almete [...] En el siglo XV puede decirse que desaparece, sustituyéndole el almete, que vino á ser su diminutivo.

$D M$ : Nombre de origen gótico, sinónimo en Castilla de «celada». 


\section{BIBLIOGRAFÍA}

\section{DICCIONARIOS}

Da: Real Academia Española (1973): Diccionario de autoridades, 3 vols., facsímil de la edición de 1726-1739, Madrid, Gredos.

DC: TERREROS, Esteban de (1987): Diccionario castellano con las voces de ciencias y artes, 4 vols., facsímil de la edición de 1786-1788, Madrid, Arco Libros.

DGLE: Diccionario general de la lengua española (1997), CD-ROM, Barcelona, Biblograf.

DILE: CASARES, Julio (1942): Diccionario ideológico de la lengua española, Barcelona, Gustavo Gili.

DM: EsTÉVANEZ, Nicolás (1897): Diccionario militar, con un vocabulario, español-francés-alemán, París, Garnier Hermanos.

DME: Alonso, Martín (1986): Diccionario medieval español. Desde las Glosas emilianenses y silenses (s. X) hasta el siglo XV, 2 vols., Salamanca, Universidad Pontificia de Salamanca.

DMEHT: Almirante, José (1869): Diccionario militar etimológico, histórico, tecnológico, con dos vocabularios francés y älémán, Madrid, Imprenta y Litografía del Depósito de la Guerra.

DRAE: REAl ACADEMIA ESPAÑola (1992): Diccionario de la lengua española, Madrid, Espasa-Calpe, 1992, $21^{a}$ ed.

Due: Moliner, María (1996): Diccionario de uso del español, CDROM, Madrid, Gredos.

GVA: LEGUINA Y VIDAL, Enrique de (1912): Glosario de voces de armería, Madrid, Librería de Felipe Rodríguez.

NHM: ESTADO MAYOR CENTRAL DEL EJÉRCITO (1954): Nomenclator históricomilitar, Madrid, Servicio Histórico-Militar.

TLCE: Covarrubias Horozco, Sebastián de (1995): Tesoro de la lengua castellana o española, ed. de Felipe C. R. Maldonado basada en el original de 1611, Madrid, Editorial Castalia, $2^{\mathrm{a}}$ ed. 


\section{EDICIONES $^{6}$}

ARDEMAGNI, Enrica, ed. (inédito): Gran conquista de Ultramar (interpolada), $B N M$ MS. 1920, Archivos magnéticos del Hispanic Seminary of Medieval Studies.

Corfis, Ivy A., ed. (1993): “Cuento de Tristán de Leonis, Rome Vatican 6428”, en Francisco Marcos Marín et al. (eds.), Archivo Digital de Manuscritos y Textos Españoles, Vol. 0, CD-ROM, Madrid, Micronet.

GAGo Jover, Francisco, ed. (1994): Texto y concordancias del Libro del cauallero Çifar, BNP MS. Esp. 36, Madison, Hispanic Seminary of Medieval Studies.

GimÉnez PaJARes, María Teresa, ed. (1992): "Nobiliario vero, BNM I 1280 (Sevilla, 1492-6-30)", en Francisco Marcos Marín et al. (eds.), Archivo Digital de Manuscritos y Textos Españoles, Vol. 1, CD-ROM, Madrid, Micronet.

HARris-Northall, Ray, ed. (1994): Text and Concordance of Gran conquista de Ultramar, BNM R-518, R-519, Madison, Hispanic Seminary of Medieval Studies.

Jonxis-Henkemans, Wilhelmina, ed. (1997): "General estoria $V$, Escorial R.I.10", en John Nitti et al. (eds.), The Electronic Texts and Concordances of the Prose Works of Alfonso X, El Sabio, CDROM, Madison, Hispanic Seminary of Medieval Studies.

KIRBY, Steven, ed. (1993): "Cantar de mío Cid. Madrid: Biblioteca Nacional, MS. Vitrina 7-17", en Francisco Marcos Marín et al. (eds.), Archivo Digital de Manuscritos y Textos Españoles, Vol. 0, CD-ROM, Madrid, Micronet.

NitTI, John y Lloyd A. KASTEN, eds. (1997): “Crónica de los conqueridores II, BNM MS. 10134 bis", en John Nitti et al. (eds.), The Electronic Texts and Concordances of Medieval Navarro-Aragonese Manuscripts, CD-ROM, Madison, Hispanic Seminary of Medieval Studies.

NitTI, John y Lloyd A. KASTEN, eds. (1997): "Plutarco I, BNP Esp. 70", en John Nitti et al. (eds.), The Electronic Texts and Concordances

6 Quiero manifestar mi agradecimiento a John J. Nitti del Hispanic Seminary of Medieval Studies, quien generosamente me proporcionó las transcripciones magnéticas inéditas de El emperador Otas de Roma, Libro de don Tristán de Leonis y Gran conquista de Ultramar (interpolada). 
of Medieval Navarro-Aragonese Manuscripts, CD-ROM, Madison, Hispanic Seminary of Medieval Studies.

SHARRER, Harvey L. et al., eds. (inédito): Libro de don Tristán de Leonis, British Library C.20.d.24. (Valladolid, 1501-2-12), Archivos magnéticos del Hispanic Seminary of Medieval Studies.

SpaCCARElli, Thomas D., ed. (inédito): El emperador Otas de Roma, Escorial h.I.13, Archivos magnéticos del Hispanic Seminary of Medieval Studies.

WrRIGHT, Diane M., ed. (1993): "Diego de San Pedro: Tratado de amores de Arnalte y Lucenda, Milan: Trivulziana 940", en Francisco Marcos Marín et al. (eds.), Archivo Digital de Manuscritos y Textos Españoles, Vol. 0, CD-ROM, Madrid, Micronet.

\section{OBRAS DE REFERENCIA}

Bruhn De Hoffmeyer, Ada (1972): Arms and Armour in Spain. A Short Survey. vol. I, The Bronze Age to the End of the Middle Ages, Madrid, CSIC, Instituto de Estudios sobre Armas Antiguas.

Bruhn De HoffMeYer, Ada (1982): Arms and Armour in Spain. A Short Survey. vol. II, From the End of the 12th Century to the Beginnings of the 15th Century, Madrid, CSIC, Instituto de Estudios sobre Armas Antiguas.

Burrus, Victoria A. (1987): A Procedural Manual for Entry Establishment in the Dictionary of the Old Spanish Language, Madison, Hispanic Seminary of Medieval Studies, $3^{\mathrm{a}}$ ed.

GIESE, Wilheim (1925): Waffen nach der spanischen Literatur des 12 und 13 Jahrhunderts, Hamburg, Seminar für romanische Sprache und Kultur.

Guerrero Lovillo, José (1949): Las Cántigas. Estudio arqueológico de sus miniaturas, Madrid, CSIC, Instituto Diego Velázquez.

MéLIDA, José Ramón (1887): Historia del casco, Madrid, Est. Tip. Sucesores de Rivadeneyra.

MENÉNDEZ PIDAL, Gonzalo (1986): La España del siglo XIII leída en imágenes, Madrid, Real Academia de la Historia.

SOLER DEL CAMPO, Álvaro (1993): La evolución del armamento medieval en el reino castellano-leonés y al-Andalus, Madrid, Servicio de Publicaciones del Estado Mayor del Ejército. 